\title{
AN INDEX FOR MEASURING HORIZONTAL DIFFERENTIATION IN HOSPITALITY
}

\author{
María D. Illescas-Manzano ${ }^{1}$ \\ Manuel Sánchez-Pérez ${ }^{2}$ (i) \\ Sergio Martínez-Puertas ${ }^{3}$
}

DOI: https://doi.org/10.31410/tmt.2020.539

\begin{abstract}
Amid a continuous and evolving offer of new services, the hospitality industry is immersed in a highly competitive changing environment, being differentiation an essential strategy to survive and gain a competitive advantage. As a consequence, a differentiation strategy is continuously being defined and adapted. Beyond the vertical differentiation, focused on objective quality signals, horizontal differentiation offers more chance and alternatives to hoteliers for using own resources and capabilities to gain a competitive advantage. In particular, product analysis and competition evaluation are a must-be to offer a value proposition co-created with the customer. Considering the great range of services, and the need to compute all properly and understandably, this work aims to design and index that can integrate all services of a hotel and allow comparison to evaluate the level of differentiation.
\end{abstract}

Keywords: Hospitality, Hotels, Horizontal differentiation, Differentiation index.

\section{INTRODUCTION}

Towadays, the activity of tourism companies is immersed in continuous change because the 1 environment moves at high speed, where tourism managers have to redesign their roadmap and define new strategies to follow, in order to lead and motivate all members of the hotel in front of the change, and to be able to ensure the correct performance and not exit from the market where they usually operate.

Hotels have to innovate continuously and not get stuck in the way they work and reach their target audience. This innovation must begin with the strategic ability to anticipate changes and achieve new opportunities in the tourism sector, generating an effort to achieve a different result. Hotels must design their value proposition by co-creating with their target and thus create the best process, image and product or services most successful.

Hotels have to take advantage of the information generated by their clients to create the best strategy to follow and thus be able to achieve the best results.

Among the strategies that a hotel can adopt are differentiation strategies, and in the tourism context these strategies have been approached through the distinction of vertical and horizontal differentiation, the first of which has been most analyzed by hotel research. Fundamentally, previous studies have addressed the analysis of vertical research strategies through the official hotel category, since this is a quality signal widely used by consumers. However, the hotel industry is traditionally considered as a sector with information asymmetries and although the official hotel classification is

\footnotetext{
University of Almería, st Sacramento (Almería) Spain

University of Almería, st Sacramento (Almería) Spain

University of Almería, st Sacramento (Almería) Spain
} 
considered an indicator of standard quality, its validity as a signal of absolute quality for the consumer has been questioned, requiring mechanisms of additional information (Abrate et al., 2011; Akerlof, 1970); various reasons question its validity, such as the fact of the coexistence of different classification systems due to the various local and national regulations (Martin-Fuentes, 2018; UNTWO 2015), the superposition of adjacent categories (Nuñez-Serrano et al., 2014), the lack of correspondence between quality and hotel categories (López-Fernández \& Serrano-Bedia, 2004).

For these reasons, hoteliers can use other types of strategies based on horizontal differentiation, for which it is essential to have an indicator that allows hotel managers to analyze the services offered by the competition. However, the analysis of these strategies has been addressed to a lesser extent by previous studies. This may be due to the existence of a wide variety of services offered within the hotel sector (Dube \& Renaghan, 2000) that makes it difficult to measure the degree of differentiation of a hotel with respect to the competition. Fundamentally, chain membership or individual availability of services have been used as indicators of the degree of differentiation, which do not take into account the offer of services from the competition. Few studies have considered alternative measurements that do take into account the competition (Urtasun \& Gutiérrez, 2017). Additionally, the development of an indicator of horizontal differentiation improves the consumer's purchasing decision-making process compared to the available offer and allows a better comparison by the consumer of the hotel price based on the services offered.

In this chapter we focus on the horizontal differentiation strategy as a competitive decision involved in providing better value to customers. In a highly competitive environment, most differentiated companies will be able to enjoy greater market power, allowing them to set higher prices (Carlton \& Perloff, 2005) due to their higher value based on designing a unique value proposition. Considering hoteliers can offer a wide and diverse range of services, and extant literature offer a limited operationalization for this strategy (Silva 2015; Urtasum \& Gutierrez 2017), present work develops a horizontal differentiation index for application in each service establishment of the hospitality industry. This index can be adapted to different context and organization, making comparisons with nearby establishments and find out differences and profiles.

One key innovation of this index is that is based on the geolocation of hotels for a more efficient and precise analysis of the competition based on the commercial area where the establishment is located. This proposal is intended to provide several contributions:

Firstly, our proposal can add the main approaches when horizontal differentiation is measuring, thus taking into account all the fundamental elements when establishing a horizontal differentiation strategy and being able to evaluate it globally with respect to the competition, surpassing thus the limitations of conventional methods to measure horizontal differentiation.

Secondly, from a business perspective, the problem of information overload has increased exponentially (Edmunds \& Morris 2000, Leeflang et al. 2014), as companies obtain different types of data (such as those related to social media, location, web traffic and clickstream) at different points in the value chain (Brown et al., 2014), being a demand to seek solutions that make it possible to take advantage of the abundance of information available to the company and generate unique knowledge for the organizational competitiveness of companies (Brown et al., 2014, Day, 2011). In this sense, our proposal aims to facilitate access to good market coverage and focus on the most successful strategy to reach potential customers (Rondán-Cataluña \& Rosa-Díaz, 2014) by aggregating the information available on the hotel offer of the competition. 
From the consumer's point of view, the overload of information, due to the wide hotel offer available today (Dube \& Renaghan, 2000), can generate a feeling of overwhelm (Bawden \& Robinson, 2009, Savolainen, 2007, Savolainen, 2015) and can generate a greater time in making decisions, lower quality of decision and lower confidence in the decision (Chervany \& Dickson, 1974). Additionally, if the information load exceeds a threshold, consumer confidence and purchase intention are negatively affected (Furner \& Zinko, 2017). In this sense, an easily interpreted horizontal differentiation indicator can, from the consumer's perspective, facilitate the purchasing decision-making process in relation to the available offer, and allow a better comparison by the consumer of the hotel price based on the services offered.

Finally, obtaining an aggregate index of horizontal differentiation with respect to the competition is of interest from the strategic perspective of the company, since, like differentiation strategies, conformity strategies also have theoretical support that supports the idea that similarity with respect to competing companies may be associated with benefits (Boulding, 1966; Eaton \& Lipsey, 1975) and that it has empirical support within the hotel sector (Lee \& Jang, 2015). Furthermore, from a strategic management point of view, it has been suggested that the optimal strategy of a company should consider a mix of differentiation and conformity (Deephouse, 1999; Irmen \& Thisse, 1998), this assumption having been verified empirically in the hotel industry (Kim et al., 2020); but, due to the high number of attributes within the hotel context, a few is known about what degree of differentiation should be adopted within a mixed strategy. Thus, within the hotel strategy, having an index that measures the degree of horizontal differentiation with respect to the competition will make it possible to evaluate in a more efficient way what is the optimal degree of differentiation that a hotel should adopt to increase its performance.

\section{VERTICAL VS. HORIZONTAL DIFFERENTIATION STRATEGIES IN THE HOSPITALITY INDUSTRY}

\subsection{Theoretical underpinnings for building a horizontal differentiation index in hospitality}

Three main theoretical views about the concept of strategy can be identified in the literature, that is, Porter's Competitive Advantage (Porter, 1985), the Resource-Based View (RBV) (Barney, 1991), an approach based on the heterogeneity of resources necessary to achieve a competitive advantage based on the theory of resources and capabilities (Barney, 1991; Peteraf, 1993), that consists of estimating the difference or similarity between the strategy or resources of a company and those of its industry (Deephouse, 1999). According to Porter (1985), a generic differentiation strategy consists of finding a unique attribute that is valuable to the customer and could provide an external competitive advantage. However, from an economic perspective, with the aim of structuring industries, two models of product differentiation have emerged based on what the product captures, i.e. its quality versus its quantities (Makadok \& Ross, 2013). We distinguish between vertical and horizontal differences (Beath \& Katsoulacos, 1991). Vertical differences are understood to mean that all products are offered at similar prices and the consumer will choose the product with the best performance. On the other hand, if the products are offered at different prices, the higher quality product will be the one with the highest price (Waterson, 1989).

Horizontal differentiation is based on the heterogeneity of consumer preferences regarding the desirable characteristics of a product or service, which means that each consumer acquires the product or service that best suits their specific preferences, being different from the preferenc- 
es of another consumer when the price of the product is the same (Cremer \& Thisse, 1991). Through horizontal differentiation, a company seeks a specific market share through a greater adaptation than the competition to the specific preferences of a part of the consumers. It aims to measure the extent to which the products offered are more attractive to certain consumers (Silva, 2015) and evaluate the best strategy based on nearby competing establishments (Urtasun \& Gutiérrez, 2017).

In the hospitality context, vertical differentiation has been analyzed through the hotel category as an indicator of quality signal (Pawlicz \& Napiella, 2017; Silva, 2015) or through similar indicators (Lee, 2015), where they implicitly adopted the assumptions of the Signaling Theory (Spence, 1973), serving the tourist to opt for one hotel or another. In addition, the hotel category is one of the most analyzed factors in hedonic price models, generating a positive effect on it (Becerra et al., 2013; Bull, 1994; Israel, 2002; Zhang et al., 2011) being the essential explanatory variable of room price (Bull, 1994; Israeli, 2002), and even the factor with the greatest impact on price (Espinet et al., 2002; Zhang et al., 2011). Additionally, the star category of a hotel is positively related to other factors of hotel quality, such as physical standards of the hotel or affiliation to quality assurance programs (Abrate et al., 2011). Finally, comment on how the hotel category is used by potential clients based on their needs and preferences so that they can choose the hotel that best suits them (Masiero et al., 2015). Extant hospitality research supports the reducing effect of vertical differentiation on pricing competition (Becerra et al., 2013; Israeli, 2002; Lee, 2015). However, it is an asymmetric effect depending on the quality of the establishment (Lee \& Jang, 2013).

Differentiation strategies have found support from various theoretical currents (Barney, 1991; Chamberlin, 1933; Carlton \& Perloff, 2005; Porter, 1991) that postulate that a more differentiated company can increase its performance.

However, the category has limitations to differentiate the hotels in terms of quality and explain the price. Thus, Abrate et al. (2011) conclude that "The lodging accommodation classification needs updating given the relevance of quality assurance programs to explain pricing. New criteria should evaluate intangible aspects related to service quality and managerial efforts to reduce the environmental impact associated with their operations" (p. 920). In addition, there may be heterogeneity caused by different local and national regulations (Martin-Fuentes, 2018; UNTWO, 2015), with great difficulty in characterizing the offer of the hotel establishments due to the great diversity of services and differences in economic development between countries. Thus, similar hotel categories between countries may correspond to different services. There is also an overlap in quality between adjacent categories (Nuñez-Serrano et al., 2014), and no correspondence between classification by quality/classification by categories (López-Fernández \& Serrano-Bedia, 2004). Extant differentiation literature has passed over this informational limitation. For these reasons, hoteliers can employ other types of strategies based on horizontal differentiation.

\subsection{Measurement of horizontal differentiation in the hospitality literature}

The research focused on the hospitality industry, shown as limitations at the methodological level for the measurement of differentiation, basically approached from the three standpoints: geographic location with respect to points of interest (Ivanov \& Piddubna, 2016; Latinopoulos, 2018; Lee \& Jang 2013; Soler et al., 2019); the link to the chain (Becerra et al., 2013) and the offer of services and amenities (Espinet et al., 2003; Yang et al., 2016). 
Concerning the first approach, geographic differentiation is mainly linked to especially important location decisions, and long-term decisions given the high relocation costs of the hotel industry (Baun \& Haverman, 1997), being insufficient to adequately characterize the entire hotel differentiation strategy.

On the other hand, chain affiliation is the most widely considered approach, despite its limitations as an indicator of horizontal differentiation, since there are variations in service quality (Antony et al., 2004); the customer may perceive differences in the service received between hotels of the same chain (Sun et al., 2017) and the reduction of asymmetry of information regarding the consumer due to the proliferation of electronic Word of Mouth and Online rankings in the hotel sector (Masiero \& Nicolau, 2016) has caused its deterioration as a sign of differentiation (Hollenbeck, 2018), being partially replaced, so that there are divergences in its impact on the room price.

Thus, there are previous studies (Balaguer \& Pernias, 2013; Becerra et al., 2013; Ivanov \& Piddubna, 2016) that conclude that belonging to a chain allows increasing the room rate; other studies concluded that its effect is not significant (Baldassin et al., 2017; Hung et al., 2010; Israel, 2002; Pawlicz \& Napierala, 2017) and finally Soler et al. (2019) found that such linkage had a negative effect.

Another methodological alternative to analyze the effect of horizontal differentiation on price is to forecast the individual effect of each infrastructure or service offered by the hotel. This alternative also has limitations, one of them being the wide variety of attributes considered by consumers in choosing a hotel (Dube \& Renaghan, 2000) and through which a hotel can differentiate itself. This high number of available services can generate inconveniences since the most common form of incorporation in hedonic models has been through the incorporation of dummy variables associated with the corresponding services, which at a methodological level, can generate multicollinearity with the hotel category (Pawlicz \& Napierala, 2017). In addition, like chain membership, there is a diversity of results on the same service depending on the destination analyzed (Baldassin et al., 2017; Latinopoulos, 2018; Lee \& Jang, 2011; Yang et al., 2016).

Finally, the main limitation of the three previous approaches is that they do not measure the level of differentiation with respect to the competition, so they do not take into account the value that the consumer receives compared to the value offered by rival products, so that the aggregate measurement of the differentiation in services of a hotel with respect to the competition through a service indicator has been considered to a lesser extent by previous studies (Silva, 2015; Sánchez-Pérez et al., 2020; Urtasun \& Gutiérrez, 2017); the indicators proposed in the approach of Urtasun \& Gutiérrez (2017) are complex and the interpretation of their value can be not very intuitive when evaluating the degree of differentiation of a company for hotel managers and the consumer, while the indicator proposed by Silva (2015) may increase its value as it incorporates a greater number of services, which can generate confusion when evaluating the degree of differentiation of a hotel. In this way, in this chapter, we will adopt an aggregate measurement approach through an indicator of easy interpretation of its value for both the consumer and the company that allows us to know the differentiation in services, with respect to the hotels of the competition, and to truly know the uniqueness of each hotel. 


\section{OPERATIONALIZATION OF AN HORIZONTAL DIFFERENTIATION INDEX IN THE HOTEL INDUSTRY}

Once all relevant theoretical concepts have been identified, the development of the differentiation index was developed through three different stages: data collection, data geolocation and index calculation.

Data collection stage. We use as an empirical setting the Spanish hotel industry, due to its size and width (Deloitte, 2018). First, a dynamic online system was developed that allowed data to be obtained from hospitality websites. This monitoring system allows you to constantly update the service offer of each establishment. The data sources used were mainly the websites of establishments with information on their activity, as well as websites of tourist intermediaries. To achieve the autonomous monitoring system, we will use tools such as R software through packages such as RCrawler (Khalil \& Fakir, 2017), as well as other similar tools for tracking and data extraction on the Internet. As a result of this first phase, information was obtained on the services offered by each hotel (Table 1), various attributes of each establishment (category, age, size), room prices, and location data (GPS coordinates).

Geolocation stage. Based on the GPS coordinates of each establishment obtained in the previous stage, each establishment was geolocated using routines programmed in $\mathrm{R}$ based on the „geosphere" and „ggmap" packages. To determine the competing establishments of each hotel, the commercial areas defined by a wholesale travel agency were considered as areas of geographic competence (Balaguer \& Pernías, 2013). Given that hotels with the same category, located in the same commercial area, are considered vertically homogeneous, in addition to obtaining the number of hotels in each commercial area, we calculate the total number of hotels with the same category for each commercial area and for all hotel categories.

Calculation of the horizontal differentiation index. For each hotel establishment $\mathrm{i}$, the horizontal distance in services with respect to the competition in its commercial area was measured. For this, each hotel establishment $\mathrm{i}$ was characterized through a vector of services Vi formed with 99 dummy variables (see Table 1) that each represent whether the corresponding service is available at hotel $i$. These dummy variables have been weighted so that those relevant services in the Italian context, like services related to the Italian historical and cultural context (Cuccule1li \& Goffi, 2016; Manrai et al., 2017; Presutti et al., 2015), have been weighted by 2, and other services related to sun and beach tourism have been weighted by $1 / 2$. For the rest of the services we have used the unit as weighting (Table 1). Given another hotel in the same shopping area Ai represented by the vector $\mathrm{Vj}$, to measure the distance between their respective service vectors (Figure 1) we consider a distance used in the product differentiation research (Chisholm et al., 2010) given by:

$$
D i f_{i j}=\left(\cos ^{-1} \frac{V_{i} \cdot V_{j}}{\left\|V_{i}\right\| \cdot\left\|V_{j}\right\|}\right) /\left(\frac{\pi}{2}\right)
$$


Table 1. Summary of hospitality services offered and weights

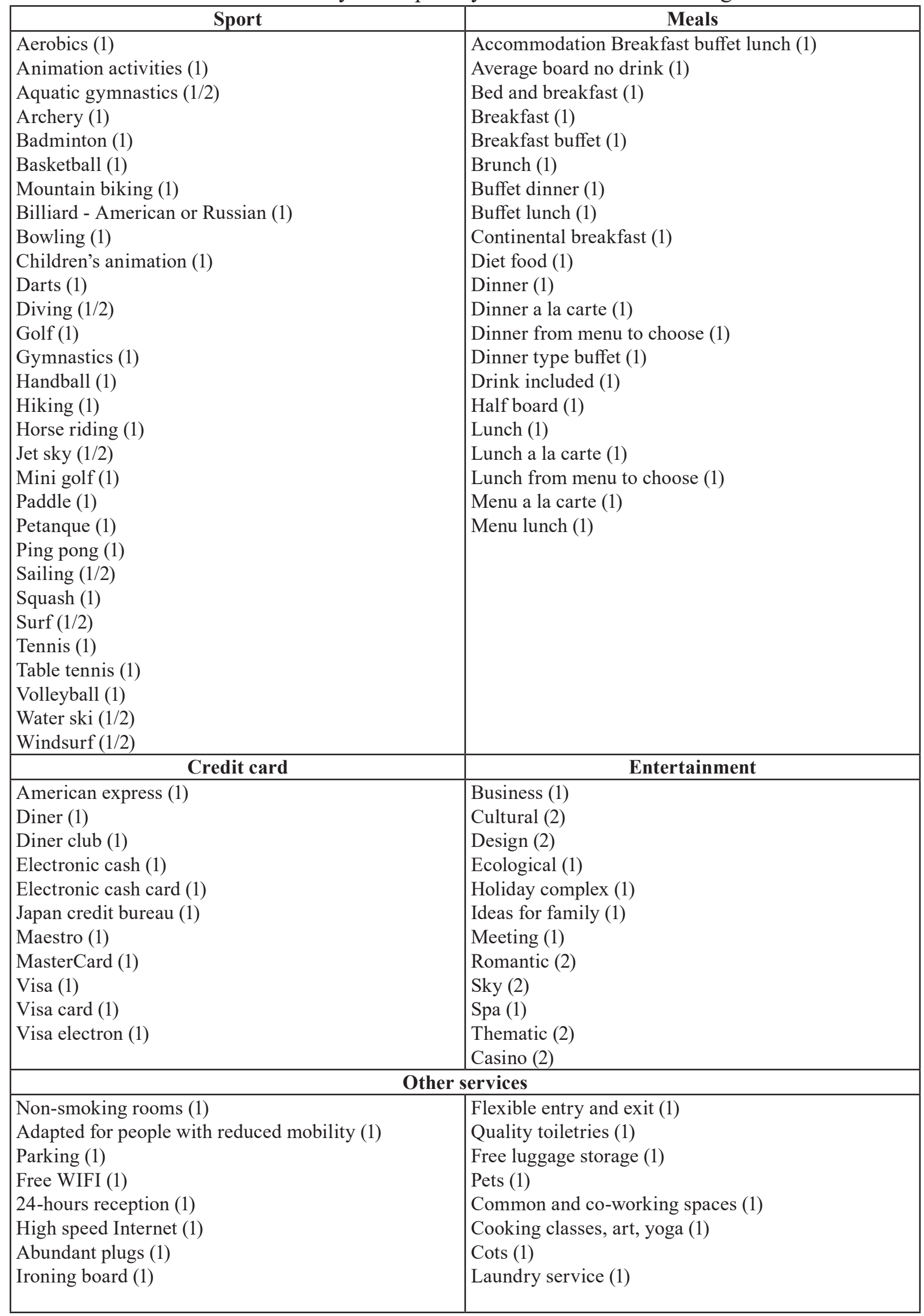




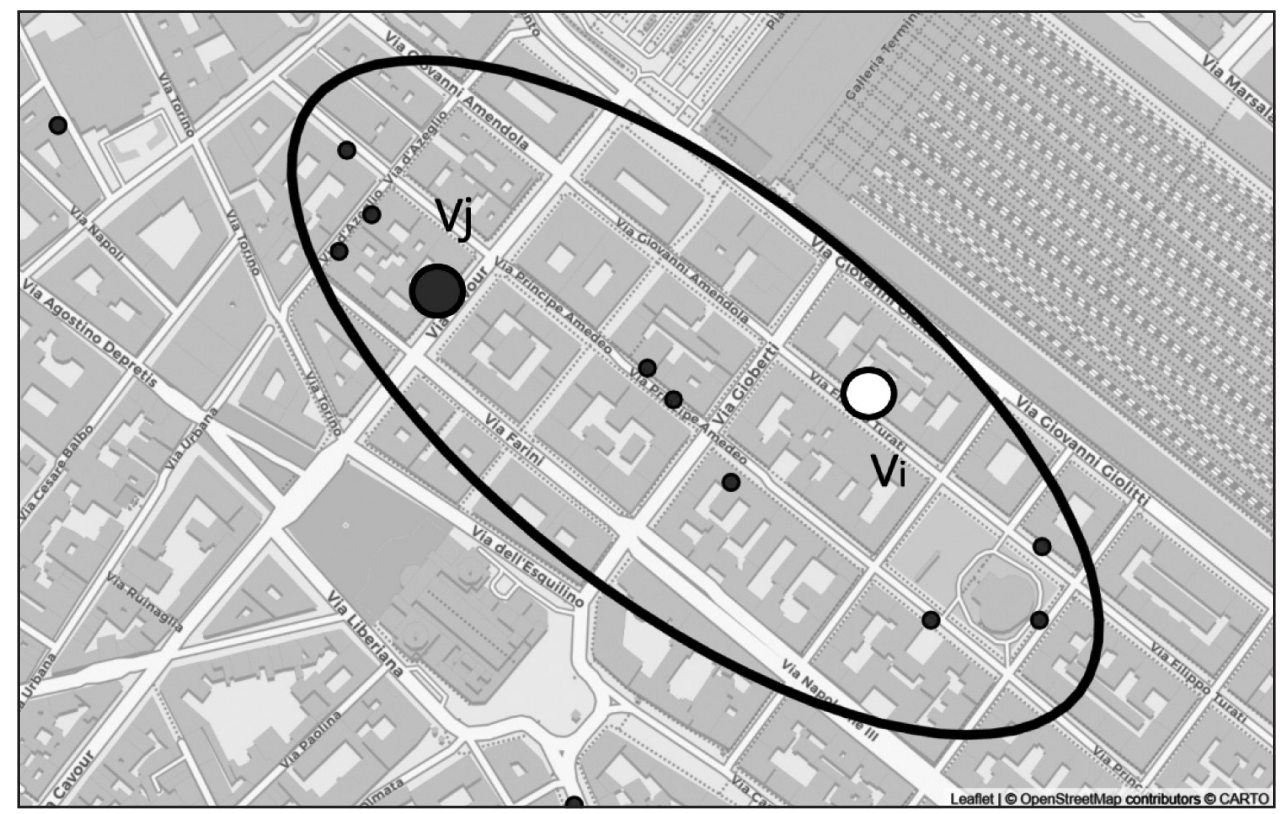

Figure 1. Comparison of the services offered for two hotels: $V_{i}$ and $V_{j}$. Source: Own elaboration through the use of OpenStreetMap ${ }^{\circledR}$ and Contributors

The distance value ranges from 0 to 1 . If the distance value is zero, the two hotels offer the same services and are not differentiated (Figure 2).

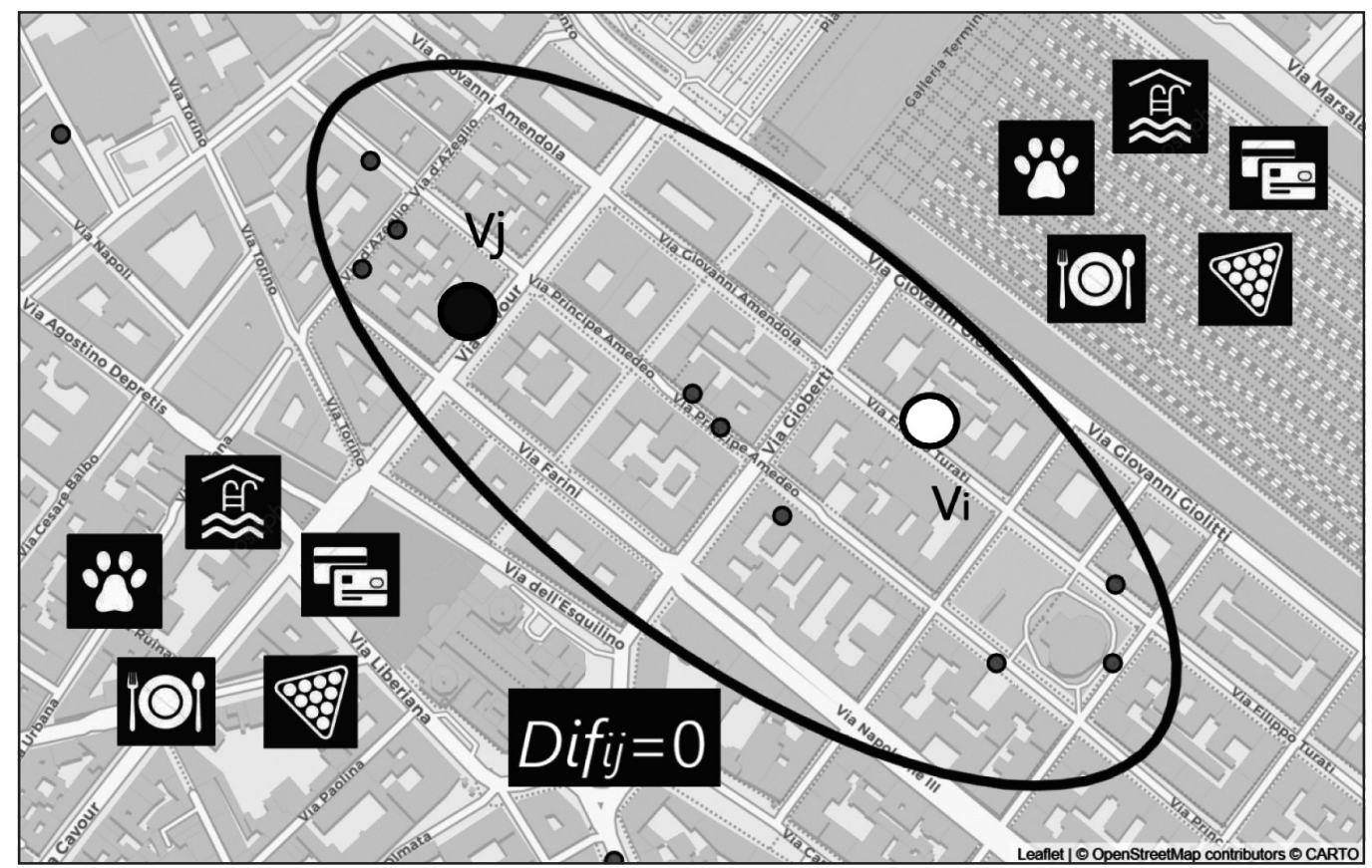

Figure 2. Case of hotels offering similar services but not differentiated Source: Own elaboration through the use of OpenStreetMap ${ }^{\circledR}$ and Contributors

If the value of the distance is 1 , the two hotels do not have overlap between the services offered by each one and they are totally differentiated (Figure 3). 


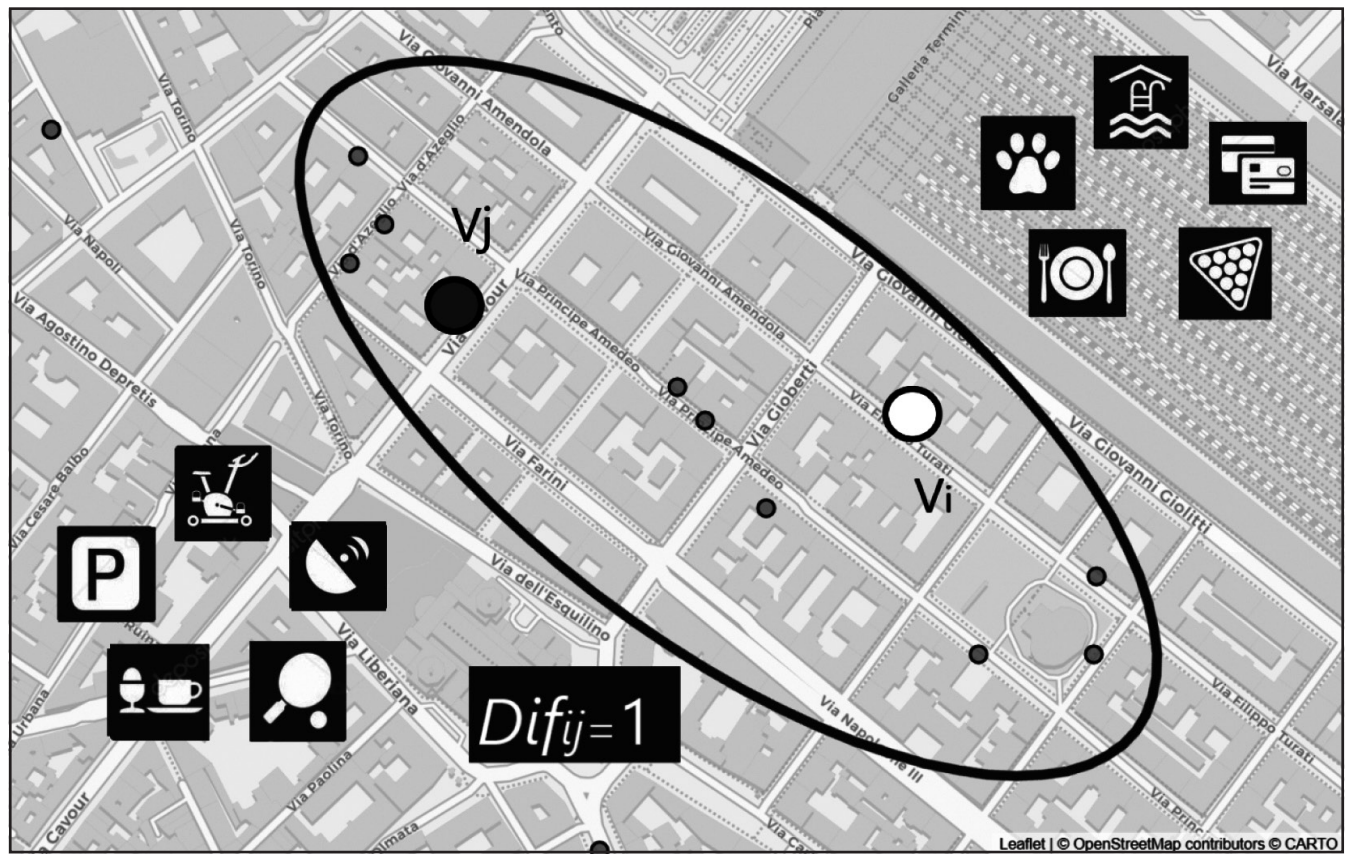

Figure 3. Case of hotels offering different services / differentiated

Source: Own elaboration through the use of OpenStreetMap ${ }^{\circledR}$ and Contributors

This operation is being repeated with the rest of the hotels in the commercial area (Figure 4).

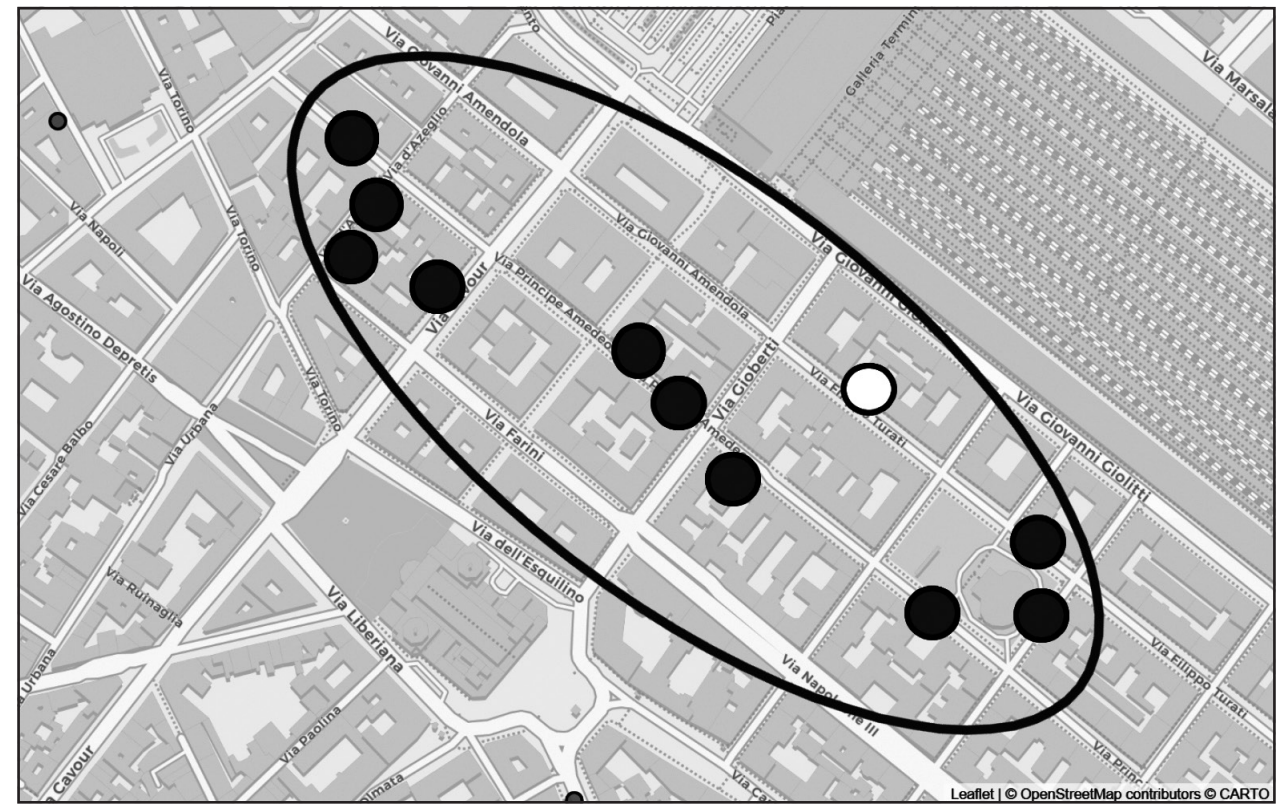

Figure 4. Case of whole set of hotels in the same area

Source: Own elaboration through the use of OpenStreetMap ${ }^{\circledR}$ and Contributors

Finally, the value of the horizontal differentiation index (H_Dif) for the hotel considered is the minimum distance obtained with respect to the competitors in its area (Figure 5), thus capturing the unique value that the hotel contributes within its commercial area:

$$
\left(H_{D i f}\right)_{i}=\min _{j \in A_{j}}\left(D i f_{i j}\right)
$$




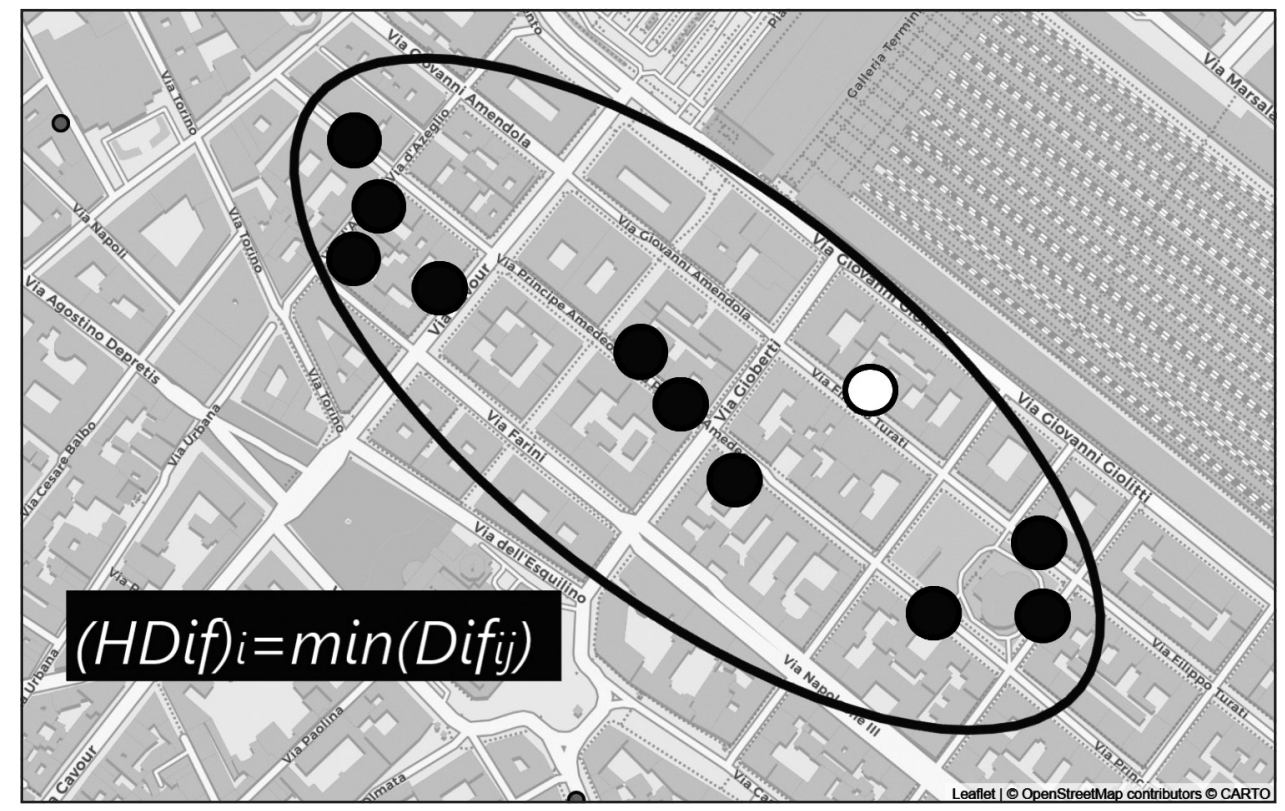

Figure 5. Calculation of the minimum distance obtained

Source: Own elaboration through the use of OpenStreetMap ${ }^{\circledR}$ and Contributors

\subsection{Index validity: Assessment in the Italian hotel industry}

In order to assess the validity of the index, we develop an empirical application. Specifically, adopting a comparative approach, we assess the usefulness of a horizontal differentiation index to analyze whether vertical and horizontal differentiation strategies in the hotel industry behave as expected, and allow prices to be increased.

For this, we have used the Italian hotel industry as a study framework in 2017 when Italy ranked fifth place in terms of international arrivals and sixth place in terms of international tourism income (World Tourism Organization, 2018). The sample of hotels in Italy includes 340 hotels in 55 cities and 151 shopping areas. With this study we intend to show a possible application of the horizontal differentiation index to empirically analyze if the vertical and horizontal differentiation strategies are determinants of the hotel price and if these types of strategies allow increasing the price or are more appropriate strategies in accordance with respect to the competition. For this we will use a hedonic price model estimated by OLS. Specifically, following previous contributions (Abrate \& Viglia, 2016; Latinopoulos, 2018) we have considered a hedonic model of semi-logarithmic prices (Rosen, 1974), to describe the impact of the independent variables on prices, since it has been the most widely-used approach to explain hotel prices (Sánchez-Pérez et al., 2019).

Thus, the variables considered in the empirical study were the following:

- $\boldsymbol{L N}$ (Price). The dependent variable is the Napierian logarithm of the yearly average room rate for a standard double room during the year 2017, considered herein as a dependent variable. We consider average room rate because it is free of price variations caused by season effect, distribution channels and events (Lee, 2015).

We consider two explanatory variables to measure vertical and horizontal differentiation:

- Category. The star rating of the hotel officially assigned by the corresponding agencies is used to represent vertical differentiation (Becerra et al., 2013) and it ranges from one to five stars. 
- $\quad$ __Dif. As horizontal differentiation degree of hotels, we consider our proposal. It ranges from 0 to 1 to represent minimum horizontal differentiation and maximum horizontal differentiation respect to competitors.

Additionally, we consider the following control variables:

- Size. Following Lee (2015) and Silva (2015), we controlled hotel size by the number of rooms because hotel size may affect hotel pricing.

- Age. We controlled hotel age by the number of years of hotel operations to account for possible differences between new hotels and old hotels (Silva, 2015)

- Competitor. Hotel's competition for each hotel is represented by the logarithm of the number of lodging establishments in the commercial area of the hotel (Becerra et al., 2013).

- Distance. This variable account for the average distance of each hotel in kilometers, with respect to other hotels in its area (Becerra et al., 2013).

Specifically, we propose the following model to analyze the impact of vertical and horizontal differentiation on hotel price:

$$
\begin{aligned}
& \text { LNPrice }{ }_{\mathrm{i}}=\beta_{0}+\beta_{1} \cdot \text { Size }+\beta_{2} \cdot \text { Age }+\beta_{3} \cdot \text { Competitors }+\beta_{4} \cdot \text { Distance } \\
& +\beta_{5} \cdot \text { Category }+\beta_{6} \cdot \boldsymbol{H}_{\text {Dif }+\varepsilon_{\mathrm{i}}}
\end{aligned}
$$

The proposed model was estimated with the sample of Italian hotel with OLS. Firstly, we analyzed the heteroscedasticity of the residuals using the Breusch-Pagan test whose results confirms the absence of heteroscedasticity in the residuals ( $p$-value $=0.133$ ). Next, we analyzed the presence of multicollinearity with the variance inflation factor (VIF). For all explanatory variables, VIF values are below 2 (Table 2) and it confirms the absence of multicollinearity in the model. Finally, Table 2 shows the results obtained in the estimation of the proposed model with OLS.

Table 2. Model estimation with OLS

\begin{tabular}{|l|l|l|l|}
\hline Variable & Coefficient & p-value & VIF \\
\hline Intercept & $2.589(9.556 \mathrm{e}-1)$ & $0.007^{* * *}$ & \\
\hline Size & $9.913 \mathrm{e}-4(3.985 \mathrm{e}-4)$ & $0.013^{* *}$ & 1.327 \\
\hline Age & $-3.204 \mathrm{e}-5(4.724 \mathrm{e}-4)$ & 0.946 & 1.036 \\
\hline Competitors & $0.071(0.018)$ & $1.280 \mathrm{e}-4^{* * *}$ & 1.914 \\
\hline Distance & $-0.074(0.012)$ & $1.11 \mathrm{e}-10^{* * *}$ & 1.186 \\
\hline Category & $0.453(0.039)$ & $2 \mathrm{e}-16^{* * *}$ & 1.291 \\
\hline $\mathrm{H}$ Dif & $0.208(0.097)$ & $0.032^{* *}$ & 1.774 \\
\hline F-statistic & 41.27 & $2.2 \mathrm{e}-16^{* * *}$ & \\
\hline $\mathrm{R}^{2}$ & 0.477 & & \\
\hline
\end{tabular}

Source: Own elaboration

Results from Table 2 show that both vertical and horizontal differentiation have a significant positive impact on hotel price. Thus, the strategy based on horizontal differentiation in Italy has a positive impact and conformity strategies penalize hotel prices. Additionally, Table 2 provides the $\mathrm{R}^{2}$ value. The value obtained indicates that the hotel price in Italy may be affected by other factors such as the valuation of the clients or the location of the hotel measured as the distance to the city center or distance to attractions. 


\section{FUTURE RESEARCH DIRECTIONS}

The information found on the Internet about the services and characteristics offered by the hotels could reach all domestic devices through the installation of a free application, and thus the consumer could be informed about the services offered by the hotels that might interest them the most at the moment of hiring, make a comparison quickly and make the most effective hiring. The range of services could be expanded through co-creation with stakeholders related to the hospitality sector and specifically with potential tourists, and thus be able to detect new potential services to offer. Another future research would be to analyze the hotel offer and the decision-making of hoteliers.

\section{CONCLUSION}

The hospitality industry is characterized by a wide and varied offering, being difficult to make comparisons and evaluation. Considering this, this work offers an index whose statistical properties have been assessed, and practical application has been illustrated.

The design of this horizontal differentiation index lets hoteliers make faster and better decisions about services that will fit best in the profile of the tourist who visits them. In addition, it can be useful to carry out a market research of focal competition, and, thus it is able to detect what the competition is offering, how it is differentiating, what is adding value with respect to the focal establishment.

Finally, this indicator, flexible, easy to understand and use, will save time and minimize risks and thus it allows the consumer to feel safe and satisfied with the hotel contracted.

\section{REFERENCES}

Abrate, G., Capriello, A., \& Giovanni, F. (2011). When quality signals talk: Evidence from the Turin hotel industry. Tourism Management, 32(4), 912-921.

Abrate, G., \& Viglia, G. (2016). Strategic and tactical price decisions in hotel revenue management. Tourism Management 55, 123-132.

Akerlof, G.A. (1970). The Market for „Lemons”: Quality Uncertainty and the Market Mechanism. The Quarterly Journal of Economics, 84 (3), 488-500.

Antony, J., Antony, F.J., \&Ghosh, S. (2004). Evaluating service quality in a UK hotel chain: a case study. International Journal of Contemporary Hospitality Management, 16(6), 380384.

Balaguer, J., \& Pernías, J.C. (2013). Relationship between spatial agglomeration and hotel prices. Evidence from business and tourism consumers. Tourism Management, 36, 391-400.

Baldassin, L., Gallo, M., \& Mattevi, E. (2017). Tourism in European cities: price competitiveness of hotels in town of artistic interest. Tourism Economics, 23, 3-28.

Barney J. (1991). Firm resources and sustained competitive advantage. Journal of Management, $17(1), 99-120$.

Bawden, D., \& Robinson, L. (2009). The dark side of information: Overload, anxiety, and other paradoxes and pathologies. Journal of Information Science, 35(2), 180-191.

doi:10.1177/0165551508095781

Beath, J., \& Katsoulacos, Y. (1991). The economic theory of product differentiation. Cambridge, NY: Cambridge University Press. 
Boulding, K. E. (4th Eds.). (1966). Economic analysis: Microeconomics. New York, NY: Harpers \& Brothers.

Brown B, Chui M \& Manyika J., (2011). Are you ready for the era of 'big data'. McKinsey Quart; 4(1): 24-35.

Becerra, M., Santaló, J., \& Silva, R. (2013). Being better vs. being different: Differentiation, competition, and pricing strategies in the Spanish hotel industry. Tourism Management, 34, 71-79.

Boulding, K. E. (4th Eds.). (1966). Economic analysis: Microeconomics. New York, NY: Harpers \& Brothers.

Bull, A.O. (1994). Pricing a motel's location. International Journal of Contemporary Hospitality Management 6(6), 10-15.

Carlton D.W., \& Perloff J. M. (2005). Modern Industrial Organization. Pearson.

Chamberlin, E. H. (1933). The theory of monopolistic competition. Cambridge, NY: Harvard University Press.

Chervany, N. L., \& Dickson, G. W. (1974). An experimental evaluation of information overload in a production environment. Management Science, 20(10), 1355-1344

Chisholm, D.C., McMillan, M.S., \& Norman, G. (2010). Product differentiation and film- programming choice: do first-run movie theatres show the same films? Journal of Cultural Economics, 34, 131-145.

Cremer, H., \& Thisse, J. F. (1991). Location models of horizontal differentiation: a special case of vertical differentiation models. Journal of Industrial Economics. 39(4):383-90.

Cucculelli, M., \& Goffi, G. (2016). Does sustainability enhance tourism destination competitiveness? Evidence from Italian Destinations of Excellence. Journal of Cleaner Production, 111, 370-382.

Day, G.S. (2011). Closing the marketing capabilities gap. J Marketing); 75(4): 183-195.

Deephouse, D.L. (1999). To be different, or to be the same? It's a question (and theory) of strategic balance. Strategic Management Journal, 20(2), 147-166.

Deloitte (2018). The hotel Property Handbook 3.0. Investment \& Financing keys. Financial Advisory Real State and Hospitality. Available at: https://www2.deloitte.com/content/dam/ Deloitte/es/Documents/financial-advisory/Deloitte-ES-Financial-Advisory-hotel-property-handbook-2018.pdf

Dube L., \& Renaghan L.M. (2000). Creating visible customer value. Cornell Hotel and Restaurant Administration Quarterly. 41:62-72.

Eaton, B., \& Lipsey, R. G. (1975). The principle of minimum differentiation reconsidered: Some new developments in the theory of spatial competition. Review of Economic Studies, 42(1), 27-49.

Edmunds A \& Morris A. (2000) The problem of information overload in business organisations: a review of the literature. Int. J. Inform. Manage.; 20(1): 17-28.

Espinet, J.M., Saez, M., Coenders, G., \& Fluiva, M. (2003). Effect on prices of the attributes of holiday hotels: a hedonic price approach. Tourism Economics, 9, 165-177.

Furner, C.P., \& Zinko, R.A. (2017). The influence of information overload on the development of trust and purchase intention based on online product reviews in a mobile vs. web environment: an empirical investigation. Electronic Markets, 27(3), 211-224.

Hollenbeck, B. (2018). Online Reputation Mechanisms and the Decreasing Value of Chain Affiliation. Journal of Marketing Research, 55(5), 636-654.

Hung, W.T, Shang, J.K, \& Wang, F.C. (2010). Pricing determinants in the hotel industry: Quantile regression analysis. International Journal of Hospitality Management, 29(3), 378-384.

Irmen, A., \& Thisse, J. F. (1998). Competition in multi-characteristics spaces: Hotelling was almost right. Journal of Economic Theory, 78(1), 76-102. 
Israeli, A.A. (2002). Star rating and corporate affiliation: their influence on room price and performance of hotels in Israel. International Journal of Hospitality Management, 21(4), 405-424

Ivanov, S., \& Piddubna, K. (2016). Analysis of prices of accommodation establishments in Kiev: determinants, dynamics and parity. International Journal of Revenue Management, 9(4), 221-251.

Khalil, S., \& Fakir, M. (2017). RCrawler: An R package for parallel web crawling and scraping. SoftwareX, 6, 98-106.

Kim, M., Roehl, W., \& Lee, S.K. (2020). Different from or similar to neighbors? An investigation of hotels' strategic distances. Tourism Management, 76, 103-960.

Latinopoulos, D. (2018). Using a spatial hedonic analysis to evaluate the effect of sea view on hotel prices. Tourism Management, 65, 87-99.

Lee, S.K., \& Jang, S.S. (2013). Asymmetry of price competition in the lodging market. Journal of Travel Research, 52(1), 56-67.

Lee, S.K., \& Jang, S.C. (2011). Room rates of US airport hotels: examining the dual effects of proximities. Journal of Travel Research, 50(2), 186-197.

Lee, S. K., \& Jang, S.C. (2015). Conditional agglomeration externalities in lodging markets. Journal of Hospitality and Tourism Research, 39, 540-559.

Lee, S.K. (2015). Quality differentiation and conditional spatial price competition among hotels. Tourism Management, 46, 114-122.

Leeflang, P.S., Verhoef, P.C., \& Dahlstróm, P., \& Freundt, T. (2014). Challenges and solutions for marketing in a digital era. European Management Journal, 32 (1), 1-12.

López-Fernández, M.C., \& Serrano-Bedia, A. M. (2004). Is the hotel classification system a good indicator of hotel quality? An application in Spain. Tourism Management, 25(6), 771-775.

Makadok, R., \& Ross, D.G. (2013). Taking industry structuring seriously: A strategic perspective on product differentiation. Strategic Management Journal, 34(5), 509-532.

Manrai, L. A., Manrai, A. K., \& DeLuca, J. (2017). Twenty shades of Italy: an analysis of its cultural, natural, and dual tourist attractions with implications for global tourism marketing. Journal of Global Marketing, 30(5), 297-308.

Martin-Fuentes, E., Fernandez, C., Mateu, C., \& Marine-Roig, E. (2018). Modelling a grading scheme for peer-to-peer accommodation: Stars for Airbnb. International Journal of Hospitality Management, 69, 75-83.

Masiero, L., \& Nicolau, J.L. (2016). Choice behaviour in online hotel booking. Tourism Economics, 22(3), 671-678.

Mazzeo, M. J. (2002). Competitive outcomes in product-differentiated oligopoly. Review of Economics and Statistics, 84(4), 716-28.

Núñez-Serrano, J. A., Turrión, J., \& Velázquez, F.J. (2014). Are stars a good indicator of hotel quality? Asymmetric information and regulatory heterogeneity in Spain. Tourism Management, 42, 77-87.

Pawlicz, A., \& Napierala, T. (2017). The determinants of hotel room rates: an analysis of the hotel industry in Warsaw, Poland. International Journal of Contemporary Hospitality Management 29, 571-588.

Peteraf, M. A. (1993). The cornerstones of competitive advantage: a resource-based view. Strategic Management Journal, 14(3), 179-191.

Porter M.E. (1985). Competitive Advantage. New York: Free Press.

Porter, M. E. (1991). Towards a dynamic theory of strategy. Strategic Management Journal, 12, 95-117. 
Presutti, M., Holt, S., \& Camillo, A. A. (2015). The glocalization of international firms: an empirical investigation in the hospitality sector. In Global Enterprise Management (pp. 135-151). Palgrave Macmillan, New York.

Rondan-Cataluña, F. J., \& Rosa-Diaz, I. M. (2014). Segmenting hotel clients by pricing variables and value for money. Current issues in tourism, 17(1), 60-71.

Rosen, S. 1974. Hedonic prices and implicit markets: product differentiation in pure competition. Journal of Political Economy, 82(1), 34-55.

Sánchez-Pérez, M., Illescas-Manzano, M.D., \& Martínez-Puertas, S. (2019). Modeling hotel room pricing: A multi-country analysis. International Journal of Hospitality Management, 79, 89-99.

Sánchez-Pérez, M., Illescas-Manzano, M. D., \& Martínez-Puertas, S. (2020). You're the only One, or Simply the Best. Hotels differentiation, competition, agglomeration, and pricing. International Journal of Hospitality Management, 85, 102362.

Savolainen R. (2007) Filtering and withdrawing: strategies for coping with information overload in everyday contexts. Journal of Information Science, 33(5), 611-621.

Savolainen R. (2015) Cognitive barriers to information seeking: a conceptual analysis. Journal of Information Science, 41(5), 613-623

Silva, R. (2015). Multimarket contact, differentiation, and prices of chain hotels. Tourism Management, 48, 305-315.

Soler, I. P., Gemar, G., Correia, M, B., \& Serra, F. (2019). Algarve hotel price determinants: A hedonic pricing model. Tourism Management, 70, 311-321.

Spence, M. (1973). Job Market Signalling. Quarterly Journal of Economics, 87(3), 355-374.

Sun, S., Tong, K.T., \& Law, R. (2017). Chinese hotel guest perception of international chain hotels under the same hotel brand in different travel destinations: The cases of intercontinental and Sheraton. Journal of Vacation Marketing, 23(2), 172-188.

UNWTO (2015). Hotel Classification systems: recurrence of criteria in 4 and 5 star hotels. Available at: https://www.e-unwto.org/doi/epdf/10.18111/9789284416646

Urtasun, A., \& Gutiérrez, I. (2017). Clustering benefits for upscale urban hotels. International Journal of Contemporary Hospitality Management, 29(5), 1426-1446.

Waterson, M. (1989). Models of product differentiation. Bulletin of Economic Research, 41(1): $1-27$

World Tourism Organization. (2018). UNWTO tourism highlights. 2018 ed. Available at: https:// www.e-unwto.org/doi/pdf/10.18111/9789284419876

Yang, Z., \& Cai, J. (2016). Do regional factors matter? Determinants of hotel industry performance in China. Tourism Management, 52, 242-253.

Zhang, Z., Ye, Q., \& Law, R. (2011). Determinants of hotel room price: an exploration of travelers' hierarchy of accommodation needs. International Journal of Contemporary Hospitality Management, 23(7), 972-981. 
